\title{
Temperaturas cardeais e efeito da luz na germinação de sementes de mutamba ${ }^{1}$
}

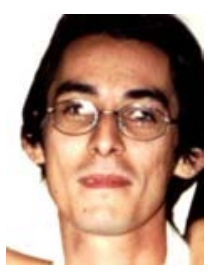

João C. de Araújo Neto ${ }^{2}$, Ivor B. de Aguiar, ${ }^{3}$ Vilma M. Ferreira ${ }^{4} \&$ Teresinha de J. D. Rodrigues ${ }^{3}$

\author{
1 Parte da Dissertação de Mestrado defendida pelo primeiro autor na FCAV/UNESP \\ 2 Eng. Agrônomo, Dr., Rua Hamilton B. Soutinho 26, Conj. Castelo Branco, Quadra 17, BI. A, Apto. 7. CEP 57035-410, \\ Maceió, AL. Fone: (82) 337-1088. E-mail: jcanetto@bol.com.br (Foto) \\ ${ }^{3}$ FCAV/UNESP. Via de acesso Prof. Paulo D. Castellane, CEP 14884-900, Jaboticabal, SP. E-mail: ivor@netsite.com.br \\ e tedelro@fcav.unesp.br \\ ${ }^{4}$ CECA/UFAL. BR 104 Norte, Km 85, Rio Largo, AL. E-mail: vmarquesferreira@bol.com.br
}

Protocolo $158-13 / 11 / 2001$

\begin{abstract}
Resumo: Guazuma ulmifolia Lam., conhecida como mutamba, é uma espécie arbórea característica dos estádios iniciais da sucessão secundária, com ampla ocorrência natural no Brasil. Possui grande potencial para recuperação ambiental de áreas degradadas. Neste trabalho, conduziram-se dois experimentos, nos quais as sementes foram extraídas e escarificadas antes da instalação dos testes de germinação. O primeiro experimento foi desenvolvido com sementes colhidas em outubro de 1995 e teve por objetivo definir as temperaturas cardeais para a germinação das sementes. Foram testadas as temperaturas de 10, 15, 20, 25, 30, 35, 40 e $45^{\circ} \mathrm{C}$, sob fotoperíodo de oito horas. Os resultados mostraram que a temperatura mínima é próxima de $10^{\circ} \mathrm{C}$, a máxima se situa entre 35 e $40{ }^{\circ} \mathrm{C}$ e as temperaturas de 25 e $30^{\circ} \mathrm{C}$ encontram-se dentro da faixa ótima. No segundo experimento, visou-se avaliar o requerimento fotoblástico de sementes recém-colhidas (colheita de outubro de 1996) e armazenadas em câmara seca por um ano (colheita de outubro de 1995). Os testes de germinação foram conduzidos a $30^{\circ} \mathrm{C}$ e as sementes recém-colhidas tiveram a germinação promovida pelas luzes branca e vermelha, mas inibida pela luz vermelhaextrema e ausência de luz. As sementes armazenadas, entretanto, revelaram-se insensíveis à luz.
\end{abstract}

Palavras-chave: Guazuma ulmifolia, semente florestal, fotoblastismo, qualidade fisiológica

\section{Cardinal temperatures and effect of light on Guazuma ulmifolia Lam. seed germination}

\begin{abstract}
Guazuma ulmifolia Lam. (Sterculiaceae) is a typical tree species of the initial stages of secondary succession in Brazil, with potential for use in restoring degraded areas. Two experiments were carried out in this work, in which seeds were extracted and scarified before conducting the germination tests. The first experiment was conducted with seeds harvested in October 1995 and aimed to determine the cardinal temperatures for seed germination. Constant temperatures of $10,15,20,25,30,35,40$ and $45^{\circ} \mathrm{C}$ were tested under an eight hour photoperiod. The results showed that the minimum temperature is around $10^{\circ} \mathrm{C}$, the maximum between 35 and $40{ }^{\circ} \mathrm{C}$, while 25 and $30^{\circ} \mathrm{C}$ temperatures are within the optimum range. The second experiment aimed to evaluate the photoblastic requirement of both freshly harvested (October 1996) and one year dry stored (harvested in October 1995) seeds. Germination tests were conducted at 30 ${ }^{\circ} \mathrm{C}$. The results showed that germination of freshly harvested seeds was promoted either by white or by red light, but inhibited by infra-red light or by darkness. Stored seeds, however, were insensitive to light.
\end{abstract}

Key words: forest seed, photoblastism, physiological quality

\section{INTRODUÇÃO}

Guazuma ulmifolia Lam. é uma espécie arbórea de médio porte, pertencente à família Sterculiaceae, de ocorrência natural em toda a América Latina (Barbosa \& Macedo, 1993). No Brasil, onde é denominada vulgarmente mutamba, ocorre desde a
Região Amazônica até o Estado do Paraná, sobretudo na floresta latifoliada semidecídua (Lorenzi, 1992). É considerada importante para a recuperação de áreas degradadas (Lorenzi, 1992; Barbosa \& Macedo, 1993) e pertence aos estágios iniciais da sucessão secundária, sendo classificada por Ferretti et al. (1995) como secundária inicial. Suas sementes possuem 
tegumento impermeável à água (Araújo Neto \& Aguiar, 1999), necessitando de tratamento pré-germinativo para germinar em maior porcentagem (Araújo Neto \& Aguiar, 2000).

A germinação das sementes é um processo biológico, cuja ocorrência se deve a um conjunto de condições ambientais específicas (Mayer \& Poljakoff-Mayber, 1982). Para muitas espécies, se fornecidas as condições ideais de luz e umidade, a temperatura predominante no solo determinará tanto a quantidade de sementes germinadas como a velocidade de germinação. Em geral, a fração de sementes que germina permanece constante, dentro de determinada amplitude de temperatura, e decresce rapidamente para valores abaixo e acima dessa amplitude (Heydecker, 1977).

O efeito da temperatura na germinação das sementes pode ser expresso em termos de temperaturas cardeais, que são mínima, ótima e máxima (Malavasi, 1988). A temperatura é chamada ótima quando ocorre máxima germinação, no menor período de tempo, e máxima e mínima, quando a germinação é zero (Borges \& Rena, 1993). O efeito da temperatura na germinação está associado às características ecológicas da espécie (Figliolia et al., 1993) e algumas espécies necessitam de alternância da temperatura para que ocorra boa germinação (Borges \& Rena, 1993; Figliolia et al., 1993). No caso da mutamba, contudo, a alternância da temperatura não favoreceu a germinação: sementes submetidas à temperatura constante de $30^{\circ} \mathrm{C}$ germinaram melhor que as submetidas à temperatura alternada de $20-30^{\circ} \mathrm{C}$ (Araújo Neto \& Aguiar, 2000).

Da mesma forma, existe grande variabilidade de respostas germinativas em função da luz. Assim, a germinação das sementes de espécies fotossensíveis pode ser estimulada ou inibida, dependendo da qualidade espectral da luz encontrada sob o dossel (Endler, 1993). Para essas respostas existe um pigmento receptor, o fitocromo, responsável pela captação de sinais luminosos, que podem ou não desencadear a germinação das sementes. Esse pigmento se apresenta em duas formas, uma ativa (FVe) e outra inativa (FV), ambas reversíveis (Toole, 1973; Azcon-Bieto \& Talon, 1993).

A forma inativa transforma-se na ativa, ao ser irradiada com luz vermelha $(620 \mathrm{~nm})$; e a forma ativa se inativa, ao ser irradiada com luz vermelha-extrema $(720 \mathrm{~nm})$. A luz branca, devido sua composição espectral e características de absorção do fitocromo, tem efeito semelhante ao da luz vermelha (Borges \& Rena, 1993). Assim, dependendo da densidade do dossel, a relação vermelho/vermelho-extremo (V/VE) pode ser alta ou baixa, proporcionando ou não a germinação de muitas sementes. Ressalta-se, porém, que determinadas sementes fotossensíveis podem desencadear a germinação, independente dessa relação.

Com base no estímulo luminoso, diversos autores têm utilizado o termo fotoblastismo para agrupar as sementes em diferentes categorias. Desta forma, sementes fotoblásticas positivas são aquelas cuja germinação é promovida pela luz branca, não germinam no escuro e são produzidas principalmente por plantas heliófilas, enquanto as fotoblásticas negativas são aquelas cuja germinação é inibida pela luz branca (Morgan \& Smith, 1981; Orozco-Segovia \& Vázquez-Yanes, 1992). Salienta-se, porém, que esta forma de agrupamento tem conduzido a muitos questionamentos, uma vez que muitas espécies heliófilas têm também germinado no escuro. Klein \&
Felippe (1991) procurando suprir tal lacuna, separaram as espécies fotoblásticas positivas em preferenciais, quando ocorre alguma germinação no escuro, e absolutas, quando a germinação é totalmente nula no escuro. Para Takaki (2001) o conceito de fotoblastismo pode ser substituído pelas formas do fitocromo que controlam a germinação, uma vez que todas as sementes possuem esse pigmento.

O presente trabalho foi desenvolvido com o objetivo de determinar as temperaturas cardeais para a germinação de sementes de mutamba e estudar o comportamento germinativo das sementes submetidas a diferentes qualidades espectrais de luz.

\section{MATERIAL E MÉTODOS}

As sementes de mutamba utilizadas neste trabalho foram extraídas de frutos maduros, caracterizados pela coloração preta e presença de fendas em sua porção inferior, colhidos de 10 árvores matrizes pertencentes a fragmentos florestais localizados no município de Jaboticabal, SP. Foram conduzidos dois experimentos: o primeiro para determinar as temperaturas cardeais e o segundo para estudar o efeito da luz na germinação das sementes. Após a colheita, os frutos foram acondicionados em sacos plásticos e armazenados em câmara seca, com $40 \%$ de umidade relativa do ar e sem controle de temperatura, até a instalação dos experimentos.

Antes do início de cada experimento, as sementes foram extraídas dos frutos e, em seguida, passadas por um divisor de solo, para uniformização das amostras. Após essa etapa, as sementes foram escarificadas quimicamente em ácido sulfúrico concentrado (95-98\%) por 50 min (Araújo Neto \& Aguiar, 2000), lavadas em água corrente por 10 min e, logo após, enxaguadas em água destilada.

Os testes de germinação foram conduzidos em germinadores tipo B.O.D., regulados para o fotoperíodo de $8 \mathrm{~h}$, fornecido por cinco lâmpadas fluorescentes de $20 \mathrm{~W}$ (luz branca, tipo luz do dia). Após a escarificação, as sementes foram colocadas sobre três folhas de papel de filtro umedecidas com água destilada, em caixas plásticas de $11 \times 11 \times 4 \mathrm{~cm}$, com tampa, e levadas para o interior dos germinadores.

O primeiro experimento foi instalado em 12 de abril de 1996, com sementes extraídas de frutos colhidos em outubro de 1995. As sementes foram submetidas às temperaturas constantes de $10,15,20,25,30,35,40$ e $45^{\circ} \mathrm{C}$, sob luz branca. Para expressar a distribuição da freqüência relativa de germinação das sementes, em cada temperatura, foi utilizada a metodologia adotada por Laboriau (1983).

O segundo experimento foi instalado em 10 de outubro de 1996, com sementes extraídas de frutos recém-colhidos e de frutos armazenados por um ano, colhidos em outubro de 1995. Os testes de germinação foram conduzidos na ausência de luz (escuro) e na presença das luzes branca, vermelha e vermelhaextrema. Utilizou-se a temperatura de $30^{\circ} \mathrm{C}$, definida como a melhor, no experimento anterior.

$\mathrm{Na}$ condição de escuro, foram utilizadas caixas plásticas de coloração preta e, na condição de luz branca, caixas transparentes. Para as outras duas condições de luz, foram utilizadas caixas transparentes colocadas no interior de envelopes, que 
funcionaram como filtro colorido. Para a obtenção de luz vermelha, os envelopes foram confeccionados com duas folhas de papel celofane vermelho e, para a obtenção de luz vermelhaextrema, quatro folhas de papel celofane, sendo duas de coloração azul e duas de coloração vermelha (Cardoso, 1995). Nos tratamentos referentes à ausência de luz e às luzes vermelha e vermelha-extrema, a semeadura e as contagens de sementes germinadas foram realizadas em ambiente iluminado com luz na faixa do verde, tida como luz de segurança.

Nos dois experimentos, consideraram-se germinadas as sementes que originaram plântulas normais com todas as estruturas essenciais, conforme prescrito nas Regras para Análise de Sementes (Brasil, 1992). As contagens de sementes germinadas foram efetuadas diariamente, até $28 \mathrm{~d}$ após a instalação do teste de germinação. Os resultados foram expressos em termos de capacidade (porcentagem final) e velocidade (índice calculado pela fórmula de Maguire, 1962) de germinação.

Os experimentos foram conduzidos sob o delineamento inteiramente casualizado, com quatro repetições de 50 sementes. Os dados obtidos foram submetidos à análise de variância e as médias foram comparadas pelo teste de Tukey, a $5 \%$ de probabilidade. Para fins de análise estatística, os valores expressos em porcentagem foram transformados em arcsen $\sqrt{\% / 100}$, mas na figura e nas tabelas estão apresentados sem transformação.

\section{RESULTADOS E DISCUSSÃO}

\section{Temperaturas cardeais}

Nas temperaturas de 40 e $45^{\circ} \mathrm{C}$ as sementes de mutamba não germinaram (Tabela 1 ), indicando que a temperatura máxima para a germinação das sementes dessa espécie se situa entre 35 e $40^{\circ} \mathrm{C}$. Embora a porcentagem de germinação obtida a $35^{\circ} \mathrm{C}$ tenha sido elevada, nessa temperatura as sementes já se apresentaram menos vigorosas, germinando em menor velocidade. Na temperatura de $40{ }^{\circ} \mathrm{C}$, a perda de viabilidade das sementes foi total e evidenciada pelo extravasamento de substâncias de odor desagradável no substrato.

O uso de temperaturas altas no processo germinativo de sementes tem ocasionado estresse, proporcionando-lhes

Tabela 1. Percentagem (PG) e velocidade (IVG) de germinação de sementes de mutamba submetidas a diferentes temperaturas constantes

\begin{tabular}{ccc}
\hline \multirow{2}{*}{$\begin{array}{c}\text { Temperatura } \\
\left({ }^{\circ} \mathrm{C}\right)\end{array}$} & \multicolumn{2}{c}{ Germinação* } \\
\hline 10 & $0,3 \mathrm{c}$ & $0,21 \mathrm{~d}$ \\
15 & $2,2 \mathrm{c}$ & $0,67 \mathrm{~d}$ \\
20 & $48,5 \mathrm{~b}$ & $2,05 \mathrm{c}$ \\
25 & $67,0 \mathrm{a}$ & $5,53 \mathrm{a}$ \\
30 & $67,6 \mathrm{a}$ & $5,73 \mathrm{a}$ \\
35 & $67,2 \mathrm{a}$ & $3,26 \mathrm{~b}$ \\
40 & $0,0 \mathrm{c}$ & $0,00 \mathrm{~d}$ \\
45 & $0,0 \mathrm{c}$ & $0,00 \mathrm{~d}$ \\
Valor de F & $153,98^{* *}$ & $102,06 * *$ \\
Coef. de variação (\%) & 15,46 & 23,72 \\
\hline * Médias seguidas de mesma letra, em cada coluna, não diferem pelo teste de Tukey, a 5\% de \\
probabilidade \\
**Significativo a 1\% de probabilidade
\end{tabular}

inibição térmica, dormência térmica ou mesmo perda de viabilidade (Vidaver \& Hsiao, 1975; Bewley \& Black, 1982). Alterações na membrana celular das sementes de várias espécies, ocasionadas por diferentes temperaturas, foram relatadas por Hendricks \& Taylorson (1976) e foram proeminentes na faixa de 30 a $35^{\circ} \mathrm{C}$, com aumento no efluxo de aminoácidos durante a germinação e decréscimo da capacidade germinativa das sementes. Segundo os autores, é provável que o efluxo de solutos, por meio de alterações metabólicas, exerça maior influência no evento que as alterações na membrana.

Nas temperaturas de 10 e $15^{\circ} \mathrm{C}$, o porcentual de germinação foi extremamente baixo (Tabela 1). Considera-se que a temperatura mínima para a germinação das sementes de mutamba esteja próxima de $10{ }^{\circ} \mathrm{C}$, uma vez que a porcentagem de germinação, a essa temperatura, foi quase nula. Considerável germinação foi constatada a $20^{\circ} \mathrm{C}$, mas as sementes germinaram em menores porcentagens e velocidade que a temperaturas mais favoráveis, cujos resultados evidenciam que as temperaturas mais baixas, testadas neste experimento, atuaram apenas bloqueando os processos metabólicos das sementes, concordando com os obtidos por Hendricks \& Taylorson (1976), para outras espécies, quando as sementes foram submetidas a baixa temperatura. Willing \& Leopold, citados por Copeland \& MacDonald (1985) mencionaram que baixas temperaturas podem interferir na expansão das membranas, possivelmente diminuindo a elasticidade e retardando a incorporação de material lipídico dentro da membrana celular em expansão.

A faixa de maior germinabilidade na qual ocorreu significativa germinação das sementes, foi de 25 a $35^{\circ} \mathrm{C}$ (Tabela 1). Dentro dessa faixa, as temperaturas de 25 e $30^{\circ} \mathrm{C}$ podem ser consideradas ótimas, pois a germinação ocorreu em maior porcentagem e mais rapidamente.

De acordo com Lang, citado por Laboriau (1983) o intervalo de temperatura de germinabilidade constante garante um mínimo de homogeneidade para que as velocidades de germinação sejam comparáveis. Em temperaturas extremas, as sementes são fisiologicamente heterogêneas, comportamento que pode ser verificado na Figura 1, onde os polígonos de freqüência relativa de germinação, em função das diferentes temperaturas estudadas, evidenciaram germinação mais homogênea nas temperaturas consideradas ótimas $\left(25\right.$ e $\left.30^{\circ} \mathrm{C}\right)$ nas quais, a curva de germinação apresentou deslocamento simétrico para a esquerda do gráfico, resultado da redução no tempo médio de germinação. Para as temperaturas mais extremas, o comportamento germinativo foi mais heterogêneo e o tempo médio de germinação foi maior.

\section{Efeito da luz}

A germinação das sementes recém-colhidas de mutamba foi influenciada pela luz, uma vez que a condição de escuro resultou em menores valores de porcentagem (Tabela 2) e velocidade (Tabela 3) de germinação. Tanto a luz branca quanto a luz vermelha proporcionaram efeito promotor na germinação, sendo esse efeito inibido quando as sementes foram iluminadas com luz vermelha-extrema, resultado que indica que o comportamento germinativo das sementes recém-colhidas, frente à luz, segue o modelo clássico das reações em que o fitocromo é ativado ao ser iluminado com luz de alta relação 

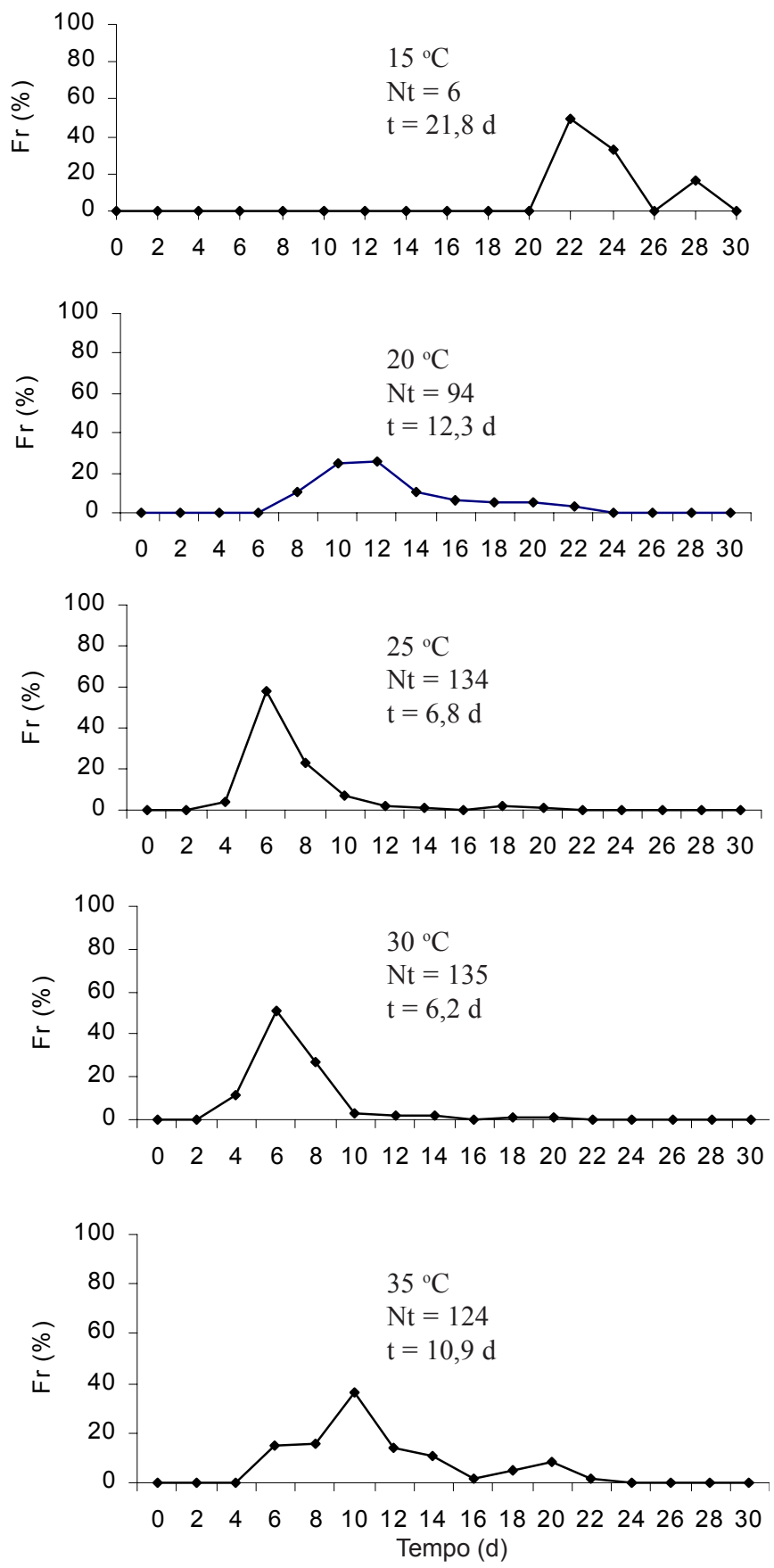

Figura 1. Distribuição da freqüência relativa $(\mathrm{Fr})$ de germinação de sementes de mutamba, em diferentes temperaturas constantes. $\mathrm{Nt}$ - número total de sementes germinadas; $\mathrm{t}$ - tempo médio de germinação (dias)

FV/FVe e inativado ao ser iluminado com luz de baixa relação FV/FVe, semelhante ao constatado para sementes de outras espécies, como Cecropia obtusifolia e Piper auritum (VázquezYanes \& Smith, 1982) e Verbesina greenmanii (Vázquez-Yanes \& Orozco-Segovia, 1982).

Do ponto de vista ecológico, o fitocromo permite a percepção de condições luminosas do ambiente. As sementes que se encontram à sombra de outras árvores, têm grande parte de seus fitocromos na forma FV, pois as folhas absorvem, preferencialmente, a luz nas faixas do azul e do vermelho. Assim, a luz que chega até o solo é predominantemente vermelha-extrema e impede a germinação das sementes de espécies que necessitam de elevado nível de FV/Ftotal. Este efeito adaptativo tende a confinar a germinação dessas sementes às clareiras, onde há maior probabilidade de sobrevivência das plântulas, devido às melhores condições de iluminação. Por outro lado, as sementes que têm sua germinação inibida pela luz, só germinam à sombra das árvores ou protegidas pela serapilheira (Vázquez-Yanes \& Orozco-Segóvia, 1990 e Orozco-Segovia \& Vázquez-Yanes, 1992).

Com base no comportamento germinativo das sementes recém-colhidas de mutamba, estas podem ser enquadradas como fotoblásticas positivas, uma vez que as sementes necessitaram de luz branca para expressar sua máxima germinabilidade (Morgan \& Smith, 1981). Seguindo o critério adotado por Klein \& Felippe (1991), elas são fotoblásticas positivas preferenciais, porque a germinação no escuro não foi nula. Com base nas formas do fitocromo que controlam a germinação, como propôs Takaki (2001), o fitocromo está controlando a germinação das sementes de mutamba através da resposta de fluência baixa (RFB). Conforme Lagôa \& Pereira (1987), esse tipo de resposta segue o modelo clássico das reações de baixa energia, onde a germinação das sementes depende das taxas de fluxo de FV para FVe, atingindo elevado nível de Fve em relação ao fitocromo total.

$\mathrm{Na}$ germinação das sementes em função da luz, deve-se levar em conta que a sensibilidade das sementes ao regime luminoso pode, também, ser alterada por outros fatores, como idade das sementes, condição de armazenamento e tratamento para superar a dormência (Toole, 1973; Bewley \& Black, 1982 e Malavasi, 1988). Segundo Laboriau (1983), a germinação das sementes expostas à luz com baixa relação FV/FVe pode ser afetada pelas condições às quais a planta-mãe foi submetida durante o período de maturação das sementes. Desta forma, a luz é detectada pela semente imatura e sua resposta germinativa pode ser consideravelmente afetada.

O comportamento germinativo das sementes de mutamba colhidas em 1995 e armazenadas por um ano, foi diferente ao das recém-colhidas. Para aquelas sementes, tanto a capacidade (Tabela 2) como a velocidade (Tabela 3 ) de germinação obtidas no escuro e sob luz vermelha-extrema, foram semelhantes às obtidas sob as luzes branca e vermelha, mostrando que as sementes de mutamba perderam a sensibilidade à luz, durante o armazenamento.

Tabela 2. Porcentagem de germinação de sementes de mutamba de diferentes idades, submetidas a diferentes qualidades de luz

\begin{tabular}{lcc}
\hline \multirow{2}{*}{ Qualidade de Luz } & \multicolumn{2}{c}{ Idade das Sementes* } \\
\cline { 2 - 3 } & Recém-Colhidas & 1 Ano \\
\hline Branca & $68,6 \mathrm{aA}$ & $61,0 \mathrm{aA}$ \\
Vermelha & $54,5 \mathrm{aA}$ & $66,8 \mathrm{aA}$ \\
Vermelha-extrema & $12,8 \mathrm{bB}$ & $55,5 \mathrm{aA}$ \\
Ausente (escuro) & $10,0 \mathrm{bB}$ & $68,3 \mathrm{aA}$ \\
F para idade das sementes (I) & $74,14^{* *}$ \\
F para qualidade de luz (L) & $24,66^{* *}$ \\
F para interação IxL & $23,51^{* *}$ \\
Coeficiente de variação (\%) & 12,51 \\
\hline * Médias seguidas de mesma letra, minúscula na coluna e maiúscula na linha, não diferem pelo teste \\
de Tukey, a 5\% de probabilidade \\
** Significativo a 1\% de probabilidade
\end{tabular}


Tabela 3. Índice de velocidade de germinação de sementes de mutamba de diferentes idades, submetidas a diferentes qualidades de luz

\begin{tabular}{lcc}
\hline \multirow{2}{*}{ Qualidade de Luz } & \multicolumn{2}{c}{ Idade das Sementes* } \\
\cline { 2 - 3 } & Recém-Colhidas & 1 Ano \\
\hline Branca & $4,41 \mathrm{aA}$ & $4,78 \mathrm{aA}$ \\
Vermelha & $3,60 \mathrm{aB}$ & $6,26 \mathrm{aA}$ \\
Vermelha-extrema & $0,64 \mathrm{bB}$ & $5,38 \mathrm{aA}$ \\
Ausente (escuro) & $0,52 \mathrm{bB}$ & $5,08 \mathrm{aA}$ \\
F para idade das sementes (I) & \multicolumn{2}{c}{$93,63^{* *}$} \\
F para qualidade de luz (L) & \multicolumn{2}{c}{$11,96^{* *}$} \\
F para interação IxL & \multicolumn{2}{c}{$10,53^{* *}$} \\
Coeficiente de variação (\%) & \multicolumn{2}{c}{23,16} \\
\hline
\end{tabular}

* Médias seguidas de mesma letra, minúscula na coluna e maiúscula na linha, não diferem pelo teste de Tukey, a $5 \%$ de probabilidade

** Significativo a $1 \%$ de probabilidade

Malavasi (1988) salientou que a influência da luz é mais forte imediatamente após a colheita e diminui à medida que as sementes envelhecem. O fator tempo, em algumas espécies, pode modificar o requerimento de luz, pela diminuição do valor da relação V/VE requerido para a germinação das sementes (Vázquez-Yanes \& Orozco-Segovia, 1987). Esse mecanismo adaptativo regula o fluxo de sementes viáveis no solo, que podem germinar quando as condições são favoráveis para o estabelecimento das plântulas (Vázques-Yanes \& OrozcoSegovia, 1984).

\section{CONCLUSÕES}

1. As temperaturas de 25 e $30^{\circ} \mathrm{C}$ encontram-se dentro da faixa ótima para a germinação das sementes de Guazuma ulmifolia (mutamba).

2. A temperatura máxima situa-se entre 35 e $45{ }^{\circ} \mathrm{C}$, e a mínima em torno de $10^{\circ} \mathrm{C}$.

3. O melhor comportamento germinativo das sementes recém-colhidas foi constatado sob luzes branca e vermelha.

4. A luz vermelha-extrema e a ausência de luz inibem a germinação das sementes recém-colhidas.

5. As sementes armazenadas por um ano revelaram-se insensíveis à luz para a germinação.

\section{LITERATURA CITADA}

Araújo Neto, J.C.; Aguiar, I.B. Desarrollo ontogénico de plántulas de Guazuma ulmifolia (Sterculiaceae). Revista de Biologia Tropical, San José, v.47, n.4, p.785-790, 1999.

Araújo Neto, J.C.; Aguiar, I.B. Germinative pretreatments to dormancy break in Guazuma ulmifolia Lam. seeds. Scientia Forestalis, Piracicaba, n.58, p.15-24, 2000.

Azcon-Bieto, J.; Talon, M. Fisiologia e bioquimica vegetal. New York: McGraw-Hill, 1993.581p.

Barbosa, J.M.; Macedo, A.C. Essências florestais nativas de ocorrência no Estado de São Paulo: informações técnicas sobre sementes, grupo ecológico, fenologia e produção de mudas. São Paulo: Instituto de Botânica e Fundação Florestal, 1993. $125 \mathrm{p}$.
Bewley, J.D.; Black, M. Physiology and biochemistry of seeds in relation to germination. New York: Springer-Verlag, 1982. $375 \mathrm{p}$.

Borges, E.E.L.; Rena, A.B. Germinação de sementes. In: Aguiar, I.B., Piña-Rodrigues, F.C.M.; Figliolia, M.B. Sementes florestais tropicais. Brasília: ABRATES, 1993. p.83-135.

Brasil. Ministério da Agricultura e Reforma Agrária. Regras para análise de sementes. Brasília: SNDA/DNDV/CLAV, 1992. $365 \mathrm{p}$.

Cardoso, V.J.M. Germinação e fotoblastismo de sementes de Cucumis anguria: influência da qualidade da luz durante a maturação e secagem. Revista Brasileira de Fisiologia Vegetal, São Carlos, v.7, n.1, p.75-80, 1995.

Copeland, L.O.; McDonald, M.B. Principles of seed science and technology. 2. ed. Minneapolis: Burgess Publishing Company, 1985.321p.

Endler, J.A. The color of light in forest and its implications. Ecological Monographs, Durham, v. 63, n.1, p.1-27, 1993.

Ferretti, A.R.; Kageyama, P.Y.; Árbocz, G.F.; Santos, J.D.; Barros, M.I.A.; Lorza, R.F.; Oliveira, C. Classificação das espécies arbóreas em grupos ecológicos para revegetação com nativas no Estado de São Paulo. Florestar Estatístico, São Paulo, v.3, n.7, p.73-77, 1995.

Figliolia, M.B.; Oliveira, E.C.; Piña-Rodrigues, F.C.M. Análise de sementes. In: Aguiar, I. B.; Piña-Rodrigues, F.C.M.; Figliolia, M. B. Sementes florestais tropicais. Brasília: ABRATES, 1993. p.137-174.

Hendricks, S.B.; Taylorson, R.B. Variation in germination and amino acid leakage of seeds with temperature related to membrane phase change. Plant Physiology, Maryland, v.58, n.1,p.7-11, 1976.

Heydecker, W. Stress and seed germination: an agronomic view. In: Khan, A.A. The physiology and biochemistry of seed dormancy and germination. Amsterdam: North-Holland Publishing Company, 1977. p.237-282.

Klein, A.; Felippe, G.M. Efeito da luz na germinação de sementes de ervas invasoras. Pesquisa Agropecuária Brasileira, Brasília, v.26, n.7, p.955-966, 1991.

Labouriau, L.G. A germinação das sementes. Washington: Secretaria Geral da O.E.A., 1983.173p.

Lagôa, A.M.M.A.; Pereira, M.F.D.A. Fotoblastismo em sementes de Ricinus communis. Revista Brasileira de Botânica, São Paulo, v.10, n.2, p.155-158, 1987.

Lorenzi, H. Árvores brasileiras: manual de identificação e cultivo de plantas arbóreas nativas do Brasil. Nova Odesa: Editora Plantarum Ltda., 1992. 382p.

Maguire, J.D. Speed of germination-aid in selection and evaluation for seedling emergence and vigor. Crop Science, Madison, v.2, n.1, p.176-177, 1962.

Malavasi, M.M. Germinação de sementes. In: Pinã-Rodrigues, F.C.M. Manual de análise de sementes florestais. Campinas: Fundação Cargill, 1988. p.25-40.

Mayer, A.M.; Poljakoff-Mayber, A. The germination of seeds. 3 ed. Oxford: Pergamon Press, 1982. 270p.

Morgan, D.C.; Smith, H. Non-photosynthetic responses to light quality. In: Lange, O.L.; Nobel, P.S.; Osmond, C.B.; Ziegler, H. Physiological plant ecology I. New York: Springer-Verlag, 1981.p.109-134. 
Orozco-Segovia, A.; Vázquez-Yanes, C. Los sentidos de las plantas: la sensibilidad de las semillas a la luz. Ciencia, Santo Domingo, v.43, p.399-411, 1992.

Takaki, M. New proposal of classification of seeds based on forms of phytochrome instead of photoblastism. Revista Brasileira de Fisiologia Vegetal, Lavras, v.13, n.1, p.103-107, 2001.

Toole, V.K. Effects of light, temperature and their interactions on the germination of seeds. Seed Science \& Tecnhology, Zürich, v.1, n.2, p.339-396, 1973.

Vázquez-Yanes, C.; Orozco-Segovia, A. Longevidad, latencia y germinación de las semillas de Verbesina greenmanii: efecto de la calidad de la luz. Turrialba, Coronado, v.32, n.4, p.457-462, 1982.

Vázquez-Yanes, C.; Orozco-Segovia, A. Fisiología ecológica de las semillas de árboles de la selva tropical: un reflejo de su ambiente. Ciencia, Santo Domingo, v.35, p.191-201, 1984.
Vázquez-Yanes, C.; Orozco-Segovia, A. Fisiología ecológica de semillas en la Estación de Biología Tropical "Los Tuxtlas", Veracruz, México. Revista de Biologia Tropical, San José, v.35, supl.1, p.85-96, 1987.

Vázquez-Yanes, C.; Orozco-Segovia, A. Light beneath the litter in a tropical forest: effect on seed germination. Ecology, Washington, v.71,n.5, p.1952-1958, 1990.

Vázquez-Yanes, C.; Smith, H. Phytochrome control of seed germination in the tropical rain forest pioneer trees Cecropia obtusifolia and Piper auritum and its ecological significance. New Phytologist, London, v.92, p.477-485, 1982.

Vidaver W.; Hsiao, A.I. Secondary dormancy in light-sensitive lettuce seeds incubated anaerobically or at elevated temperature. Canadian Journal of Botany, Ottawa, v.53, n.22, p.2557-2560, 1975. 